\title{
Astragalus Polysaccharides Enhance the Immune Response to Newcastle Disease Virus Vaccination in Chickens
}

\author{
D.O.I - 10.51201/Jusst12542 \\ http://doi.org/10.51201/Jusst12542 \\ A .I . Naji and Huda. S.J \\ Department of Microbiology, college of veterinary medicine, University of Baghdad, Iraq.
}

\begin{abstract}
This study was conducted to evaluated the effects of Astragalus polysaccharide on immune responses of chickens immunized with NDV Lasota vaccine. One hundred chickens at one-day-old( Ross breed) were brought, on five day of age, the average maternal serum Abs was measured by hemaglutination inhibition (HI) test and the titer was $3.43 \mathrm{log}$, and then divided into five equal groups in each group twenty chicks and on day 10 of age the Astragalus polysaccharide high concentration (APSH) group were given $0.5 \mathrm{ml}$ at $400 \mathrm{mg} / 100 \mathrm{ml}$, the Astragalus polysaccharide medium concentration (APSM )group were given $0.5 \mathrm{ml}$ at 200mg /100ml, the Astragalus polysaccharide low concentration (APSL) group were given $0.5 \mathrm{ml}$ at 100mg $/ 100 \mathrm{ml}$, Vaccine control (VC) group were given $0.5 \mathrm{ml}$ normal saline only, Negative control (NC) group were given normal saline only, all groups orally administrated for four days. At 14 day of age, all chickens with the exception of NC group, were vaccinated with ND Lasota by Intraocular and Intranasal methods. Four blood sample from all groups were aspirated from jugular vein at $0 \mathrm{~h}$ (before vaccination),6h,12h and $24 \mathrm{~h}$ (after vaccination) for determine of Chicken IL-6(Interleukin 6) by RT-PCR. On day 20and 30 of age after vaccination, three chicken were sampled randomly from each group to detect specific serum Antibody titer of NDV by HI test. On days 1,7,14,21after vaccination, four serum Samples from the same of chicken to determines IgA level by sandwich ELISA test. The cellular and humeral response including the production of cytokine IL-6 ( by RT-PCR test) were measured on Oh(before vaccination), $6 \mathrm{~h}, 12 \mathrm{~h}$ and $24 \mathrm{~h}$ (after vaccination ) and IgA antibody ( by ELISA test ) were measured on 1d,7d,14d, and 21days after vaccination and serum antibody titer Specific to NDV( by HI test ) were measured at age 20, and 30 days after vaccination evaluated by series of experiments. Results

revealed that all the polysaccharide groups were numerically increased in antibody levels, the expression of IL-6and IgA level, but three parameter were significant $\$ 0.05)$ in the APSH group compared to corresponding (VC) vaccinated group and $(N C)$ non

-vaccinated group. These results suggest that orally administered APS could significantly enhance the efficacy of NDV vaccination and has important implications for the further use of APS as a novel adjuvant.
\end{abstract}

Keywords: immune response, Astragalus polysaccharide, ND vaccine,IL-6, IgA. 


\section{Introduction}

Newcastle disease virus (NDV), is regarded as one of the two most devastating diseases of poultry with the characteristics of serious disease and high flock mortality (1) there were no effective drugs to treat this disease and the main method to control ND was vaccination (2). Despite routine vaccination programs, outbreaks of ND have frequently occurred in Iraq (3) and still hard to control due to the variation of strain, the inferior quality or improper conservation and transportation of vaccines, or the occurrence of immunosuppressive disease. It is considered that the application of vaccine with immunopotentiator could improve the efficacy of vaccination. (4).

Astragalus polysaccharides (APS), which are active ingredients extracted from the Chinese medicinal herb Astragalus, were shown to have multiple biological activities, including immunomodulatory (5), anti-inflammatory (6), and antiviral effects(7). APS is widely used as an immune adjuvant; having been identified as a class of macromolecule that can profoundly affect the immune system, stimulate cell proliferation, induce the expression of surface antigens on lymphocytes, affect the expression of cytokines, and promote the production of antibodies( 8). Interleukin-6 is a multifunctional cytokine that plays a major role in regulating immune responses and acute-phase reactions (9).

Interleukin-6 is produced by many different cell types and acts on B lymphocytes (10), T lymphocytes ,hepatocytes (11). Astragalus polysaccharides commonly used in Chinese medicines to enhance the immune response demonstrated slight improvements in the humoral immune response to NDV vaccination with or without sulfation(12).

IgA is considered as provides potent immunity against a large number of viral infections(13). In a previous study, it was reported that APS possess effective immunestimulatory effects when used in vaccination programs against Foot and mouth disease virus (FMDV), Avian influenza (AI) and Infectious bursal disease virus (IBDV) $(14,15)$ Therefore, the aim of this study was studied how APS affected antibody titer, in mRNA expression of IL-6, and in IgA level.

\section{2-Materials and methods}

\section{APS, and ND vaccine}

APS (net content, 98\%) was purchased from China and was dissolved in saline at a concentration of $400 \mathrm{mg} / 100 \mathrm{~mL}, 200 \mathrm{mg} / 100 \mathrm{ml}, 100 \mathrm{mg} / 100 \mathrm{ml}$ to administrate $0.5 \mathrm{ml}$ to study groups by orally gavage for four consecutive days (16). ND vaccine, Live attenuated Newcastle virus vaccine contains Lasota strain(Cevax® New L- France). 


\section{Animals}

One hundred -1-day-old( Ross,308) breed broilers were purchased from Al-Shuker hatchery located in Abu Ghraib area to carry out this experiment. The experiment was done in poultry Farm of the avian pathology unit in the College of( Veterinary Medicine in Baghdad University ,Iraq ). All chicken were bred in wire cages in an air-conditioned room maintained at $37 \mathrm{C}$ and lighted for $24 \mathrm{~h}$ during the pretrial period. Then, the temperature was gradually decreased to room temperature, and the lighting period was changed to $12 \mathrm{~h}$ per day. Chickens were fed with commercial starter diet. At day five of age measured maternal Abs specific ND virus by HI assay and was the average Abs $3.43 \log _{2}$

\section{Experimental design}

The aforementioned 100 avian broilers were randomly divided into 5 groups of 20 birds each : three oral APS groups, one vaccine control group (VC) and one nonvaccinated negative control group (NC). At ten days old three groups were given $0.5 \mathrm{ml}$ orally administered different concentration of Astragalus polysaccharide (high, 400 mg/100mL ;medium,200mg/100ml ;low 100mg/100ml), referred to as: APSH, APSM, and APSL, respectively, while, two other groups were given $0.5 \mathrm{ml}$ normal saline , once a day for 4 successive days. All chickens with the exception of NC group were vaccinated with ND Lasota vaccine $(0.03 \mathrm{ml})$ by Intraocular and Intranasal methods at age 14 day. Then serum sample to determine specific anti-ND antibody by HI test, blood sample to determine IL-6 gene expression by RT-PCR and serum sample to determine IgA level by sandwich ELISA test.

\section{Detection of specific anti-ND antibody by HI assay}

Blood samples (1.0 $\mathrm{ml}$ per chick), Three from each group were drawn into Eppendorf tubes from the jocular vein of chicken and allowed to clot at $37 \mathrm{C}$ for $2 \mathrm{~h}$. The serum was separated by centrifugation and stored at $20 \mathrm{C}$ for $\mathrm{HI}$ antibody assay. Briefly, after the serum was inactivated at $56 \mathrm{C}$ for $30 \mathrm{~min}$, twofold serial dilution were made in a 96-well $\mathrm{V}$-shaped bottom microtiter plate containing $25 \mu \mathrm{l}$ of normal saline in each well, then 25 $\mu \mathrm{l}$ of NDV antigen (4 HA units) was added into all the wells except for the last row as the controls. Serum dilutions ranged from 1:2 to 1:2048. The plate was incubated at $37 \mathrm{C}$ for $10 \mathrm{~min}$, then $25 \mu \mathrm{l}$ of $1 \%$ rooster erythrocytes suspension was added to each well and continued to incubate for $30 \mathrm{~min}$. A positive serum, a negative serum, erythrocytes and antigens were also included as controls. The highest dilution of serum caused complete inhibition was considered the endpoint. The geometric mean titer was expressed as reciprocal $\log 2$ values of the highest dilution that displayed HI (17). 


\section{Real time quantitative RT-PCR (one-step RT-qPCR)}

The total RNA was extracted from blood using Trizol reagent ,blood samples(four from each group) according to the protocol of TRIzol ${ }^{\mathrm{TM}}$ Reagent(Thermo Scientific ,USA). Reverse transcription and qPCR reaction were achieved in a single tube by using LyoMix-RT-qPCR . One-Step protocol according to The IL-6 chicken GeneExpres RTqPCR kit was provided from Genetic PCR Solutions ${ }^{\mathrm{TM}}$, (Spain) Company. Interpretation of results by Copy number $=10(\mathrm{Ct}-$ Yinter $)) /($ Slope $)$.

\section{Determined of serum IgA level}

Serum samples, four sample from each group, were harvested from the five groups of chickens . On days1,7, 14, and 21 after the immunization for IgA level assay . Total serum IgA level was measured with double antibody sandwich ELISA kit (My Biosource, USA) according to the manufacturer's instructions. The optical density (OD) at $450 \mathrm{~nm}$ was measured in a micro plate reader .

\section{Statistical analysis}

The Statistical Analysis System- SAS (2012) program was used to detect the effect of difference factors in study parameters. Least significant difference -LSD test (Analysis of Variation-ANOVA) was used to significant compare between means in this study.

\section{3-Results}

\section{Effect of APS on Antibody titer determined by HI assay}

The mean titer of maternal specific serum antibody to NDV by using HI test at day fife of age was 3.43 ,therefor vaccination at old 14 day .The dynamic changes of serum antibody response to NDV vaccination in different groups of chicken on age 20,30 days after vaccination are shown in Fig.1. On age 20 days, antibody response of vaccinated groups increase but with no significant different, while in APSH group was significantly increase $(\mathrm{p}<0.05)$ than all the other groups ( APSM, APSL ,VC, NC) groups and no significant different $(\mathrm{p} \leq 0.05)$ among ( APSM, APSL ,VC, NC) groups. On age 30 days post-vaccination, the titer Abs in APSH group was significantly higher $(\mathrm{p}<0.05)$ than ( APSM, APSL, VC, NC ) groups, while in APSM group and APSL group with significantly higher $(\mathrm{p}<0.05)$ than $\mathrm{NC}$ group and no significant different $(\mathrm{p}<0.05)$ from $\mathrm{VC}$ group and the titer $\mathrm{Abs}$ of $\mathrm{VC}$ group with significantly higher $(\mathrm{p}<0.05)$ than NC group . 


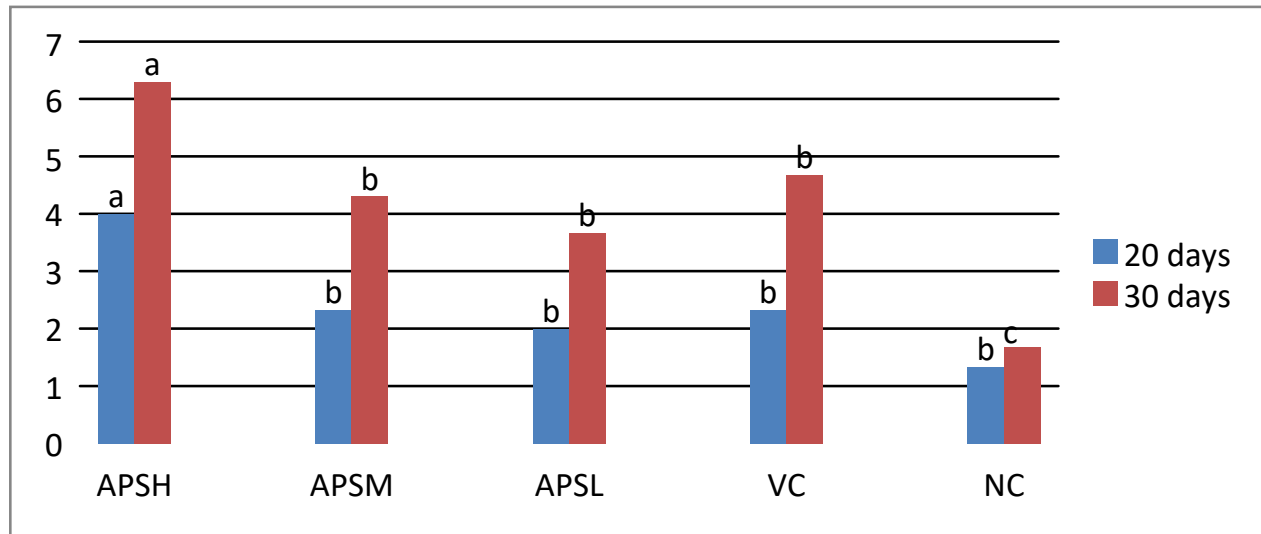

Figure(1):

Effect

APS(Astragalus polysaccharide) on Antibody titer at age 20,30 days post vaccination

(superscripts with different letters $(\mathbf{a}, \mathbf{b}, \mathbf{a b})$ differ significantly $((\mathbf{P} \leq \mathbf{0 . 0 5})$.

APSH=Astragalus polysaccharide high concentration $(400 \mathrm{mg} / 100 \mathrm{ml})$ group. APSM=Astragalus polysaccharide Medium concentration $(200 \mathrm{mg} / 100 \mathrm{ml})$ group. APSL=Astragalus polysaccharide Low concentration $(100 \mathrm{mg} / 100 \mathrm{ml}$ APSL) group. $\mathrm{VC}=$ vaccinated control group. $\mathrm{NC}=$ non- vaccinated negative control group

\section{The effect of APS on IL-6 expression}

The gene expression of IL-6 was analyzed using RT-PCR, as shown in Figure 2. On Zero hour before vaccination and six hour after vaccination, gene expression of IL-6, with no significant different $(\mathrm{p}<0.05)$ among the five study groups( APSH, APSM, APSL, VC ,NC).On12 hour after vaccination, IL-6 gene expression in VC group was numerically greater than NC group but with no significant different $(\mathrm{p}<0.05)$ and in APSH group and APSM group higher than VC group with no significant different $(p<0.05)$ but were significantly higher than that in NC group $(\mathrm{P}<0.05)$. The expression of IL-6 gene in APSL group was no significant different $(\mathrm{p}<0.05)$ than $\mathrm{VC}$ group. On 24hour after vaccination, the gene expression of IL-6 value in VC group increase with no significant different $(\mathrm{p}<0.05)$ than NC group, and in the three APS groups(APSH,APSM,APSL) ,the IL-6 expression were increased, but with no significant differences among the three APS groups $(\mathrm{P}<0.05)$, and only those of the APSH group were significantly $(\mathrm{P}<0.05)$ larger than those in VC and NC group, and in APSM group was significantly higher than that in NC group $(\mathrm{P}<0.05)$. 


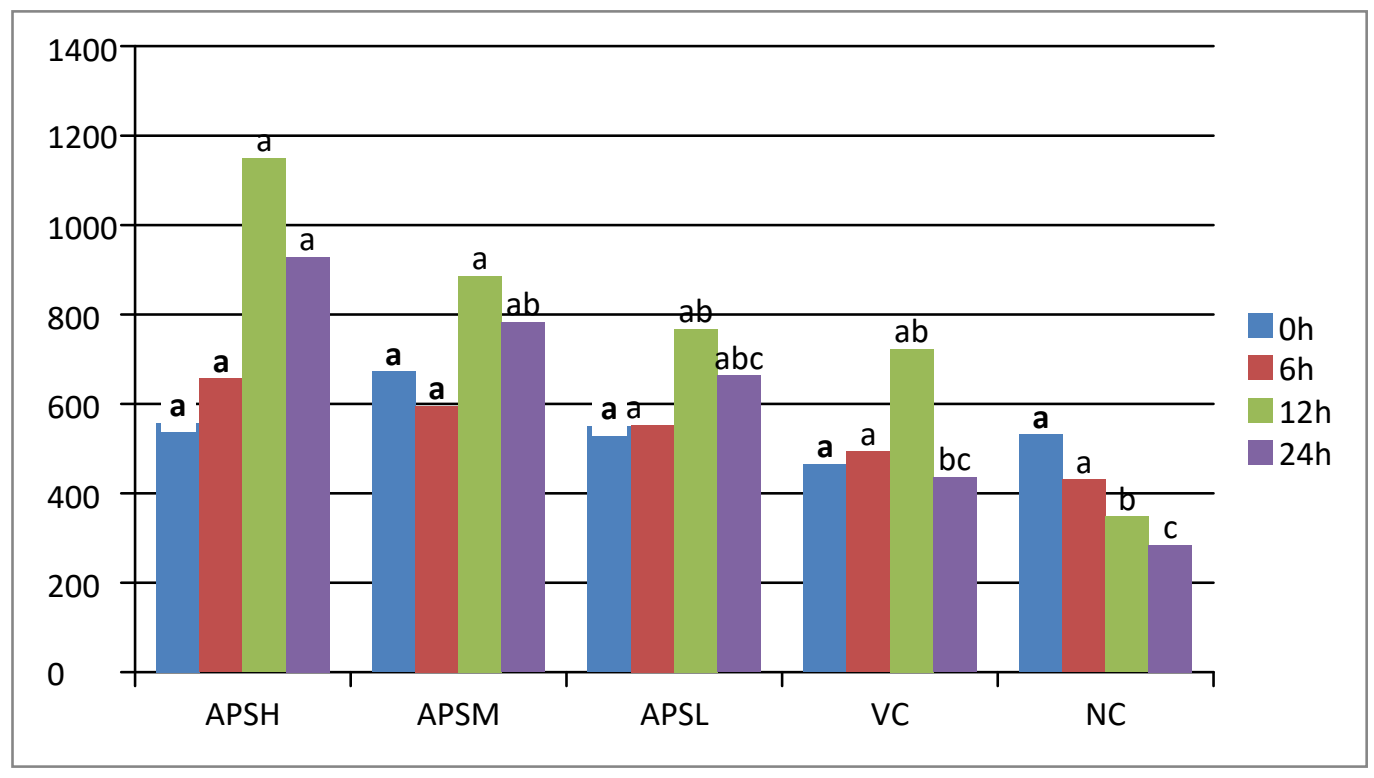

Figure (2):Effect of APS on IL-6 gene expression by RT-PCR at(0h)before vaccination while on $6 \mathrm{~h}, \mathbf{1 2 h}, \mathbf{2 4 h}$ groups after vaccination.

(superscripts with different letters $(\mathbf{a}, \mathbf{b}, \mathbf{a b})$ differ significantly $((\mathbf{P} \leq \mathbf{0 . 0 5})$.

APSH=Astragalus polysaccharide high concentration $(400 \mathrm{mg} / 100 \mathrm{ml})$ group. APSM=Astragalus polysaccharide Medium concentration $(200 \mathrm{mg} / 100 \mathrm{ml})$ group. APSL=Astragalus polysaccharide Low concentration $(100 \mathrm{mg} / 100 \mathrm{ml}$ APSL) group. $\mathrm{VC}=$ vaccinated control group. $\mathrm{NC}=$ non- vaccinated negative control group

\section{The effect of APS on IgA level}

As shown in Figure 3, the serum $\operatorname{IgA}$ level(ng/ml) was analyzed using ELISA. On day 1 after immunization, the serum IgA levels of all APS treated groups were with no significant different (? > 0.05) from VC group and NC. On day 7 after vaccination , serum IgA level(ng/ml) in the three APS groups (APSH,APSM,APSL) were increased, but only those of the APSH group were significantly $(\mathrm{P}<0.05)$ larger than those in VC group and NC group. On day14( after vaccination ), serum IgA level(ng/ml) in APSH ,APSM,APSL and VC groups were significantly $(\mathrm{P}<0.05)$ higher than those in NC group ,but the values in APSH group were significantly $(\mathrm{P}<0.05)$ higher than those in VC group and were significantly $(\mathrm{P}<0.05)$ higher than those in APSM group and APSL group. On day 21 after vaccination, serum IgA level( $\mathrm{ng} / \mathrm{ml})$ in APSH group and APSM group were significantly $(\mathrm{P}<0.05)$ higher than those in VC group and NC group, but the value in APSL were significantly $(\mathrm{P}<0.05)$ higher than those in NC group only, and serum IgA level in VC group was significantly $(\mathrm{P}<0.05)$ higher than NC group , and when compared among the values of serum IgA level in three treated APS groups only those in APSH group were significantly $(\mathrm{P}<0.05)$ higher than those in APSM group and APSL group . 


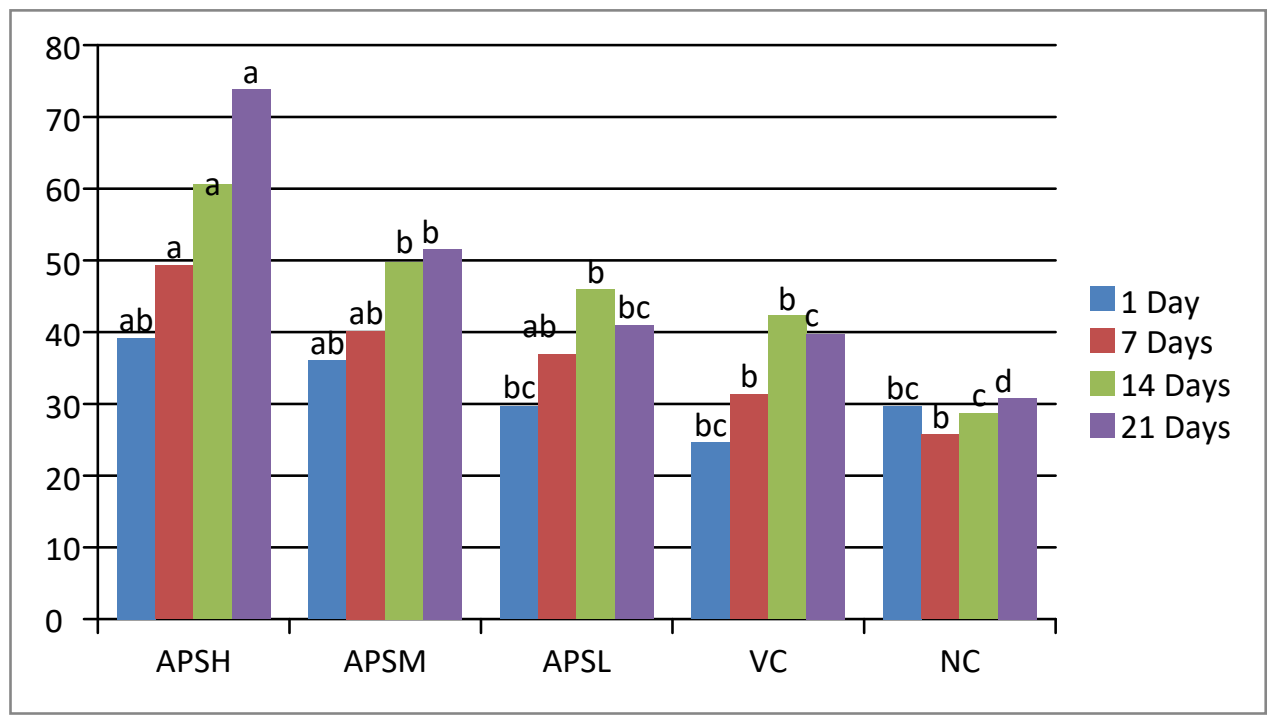

Figure (3): Serum concentration of $\operatorname{IgA}(\mathrm{ng} / \mathrm{ml})$ among experimental groups determine by ELISA at different time after vaccination

(superscripts with different letters $(\mathbf{a}, \mathbf{b}, \mathbf{a b})$ differ significantly $(\mathbf{P} \leq \mathbf{0 . 0 5}))$.

APSH=Astragalus polysaccharide high concentration $(400 \mathrm{mg} / 100 \mathrm{ml})$ group. APSM=Astragalus polysaccharide Medium concentration $(200 \mathrm{mg} / 100 \mathrm{ml})$ group. APSL=Astragalus polysaccharide Low concentration $(100 \mathrm{mg} / 100 \mathrm{ml}$ APSL) group. $\mathrm{VC}=$ vaccinated control group. $\mathrm{NC}=$ non- vaccinated negative control group

\section{Discussion}

The changes of serum antibody titer in poultry reflected the state of humeral immunity (18). Serum HI Ab titer is a valid indicator of the humoral immunity in chickens (19) The high level of antibody titer has always been associated with better protection against ND (12). The result of this study indicate that HI antibody titer of maternal derived antibody in serum of chickens at five days of age was $3.43 \log 2$, these results may explain that breeders might to previously vaccinated by live attenuated and inactive NDV vaccines for many times which eventually gave a high titer of $\operatorname{IgY}$ in the sera of breeders(20). chicks at one to three days of age have circulating antibodies in similar concentrations to those found in dams then the titers fall to be undetectable level by 14-30 days, according to this reason in the present study, the vaccination performed in day 14th of chickens age, In this study, the antibody titers after vaccination with ND vaccine(Lasota vaccine ) at day 20th and day 30th of age in APSH(400mg/100ml )group was higher than all the other groups (APSM,APSL,VC,NC) that indicate extract that synergistic or support with vaccine to providing protection from the disease. Chen et al (21) reported that APS increased the NDV antibody titer in the serum of broiler chickens, and could significantly improve the immune efficacy of the NDV vaccine. 
IL-6 has many functions in the regulation and coordination of the immune system, metabolism $(22,23)$. It plays a role in the body's defense against infection, in many regenerative processes (23). The results of the current study proved presence increase of IL-6 gene expression in vaccinated and APS treated groups (APSH,APSM,APSL) and VC (vaccinated group) Compared to $\mathrm{NC}$ ( control group) at 12 hour and 24hour after vaccination, this may be attributed to ability of ND Lasota vaccine to express chickens IL-6 at early response. Rue et al ( 24) indicate that many genes associated with an early innate host response were induced by NDV at 24 hour post infection, and that including the proinflammatory cytokine IL-6 . This study recorded that on 24 hour after vaccination the IL-6 gene expression of APS treated groups and vaccinated (APSH,APSM,APSL) were higher than corresponding VC (vaccinated control group) and NC (non- vaccinated negative control group). The up-regulations of IL-6 in the present study agreed with Sun et al (25) that higher immune responses of APS treated groups after vaccination with the ND vaccine.

In this study, On day 1 after immunization, the serum $\operatorname{IgA}$ levels among of all experimental groups(APSH, APSM,APSL, VC,NC) no significant difference (? > 0.05) due to Antibody usually appears within 6-10 days after infection in the blood( 26) and this is what was found on day 7 after vaccination, serum IgA level in the three APS groups(the chicken were oral administration with different concentration of APS $(400,200,100 \mathrm{mg} / 100 \mathrm{ml})$ and vaccination with ND vaccine(Lasota strain)) were increased, but only those of the APSH $(400 \mathrm{mg} / 100 \mathrm{ml}$ group) were significantly $(\mathrm{P}<0.05)$ larger than those in VC (vaccinated control group) and $\mathrm{NC}$ (non- vaccinated control group) that indicate APSH(400mg/100ml group ) enhance of IgA levels compere VC group that vaccinated only and over time increase $\operatorname{IgA}$ levels that were note on day 14,21 after vaccination this results agree with Shan et al (27) the results showed that oral administration of APS could significantly increase IgA+ cell expression in the jejunal lamina propria, and enhance the level of NDV specific sIgA antibodies after ND vaccine. Therefore, oral administration of APS could enhance the intestinal mucosal immune function of chickens, and APS could be used as a vaccine enhancer. 


\section{References}

1.Aldous E.W \& Alexander D.J. 2008. Newcastle disease in pheasants (Phasianus colchicus): A review. The Veterinary Journal. 175(2): 181-185.

2. Rauw, F., Gardin, Y., Palya, V., Anbari, S., Gonze, M., Lemaire, S., ... \& Lambrecht, B. (2010). The positive adjuvant effect of chitosan on antigen-specific cell-mediated immunity after chickens vaccination with live Newcastle disease vaccine. Veterinary immunology and immunopathology, 134(3-4), 249-258.

3. Al Shammari, A. M., Hamad, M. A., AL Mudhafar, M. A., Raad, K., \& Ahmed, A. (2020). Clinical, molecular and cytopathological characterization of a Newcastle disease virus from an outbreak in Baghdad, Iraq. Veterinary Medicine and Science.

4. Xie QG. Progress in the study of grave epidemic diseases immune prevention and cure of domestic animals and poultry. Beijing: Chinese Agricultural Science and Technology Press; 1995. p. 143-68.

5. Wang, Y., Chen, Y., Du, H., Yang, J., Ming, K., Song, M., \& Liu, J. (2017). Comparison of the anti-duck hepatitis $A$ virus activities of phosphorylated and sulfated Astragalus polysaccharides. Experimental Biology and Medicine, 242(3), 344-353.

6. Wang, X., Li, Y., Yang, X., \& Yao, J. (2013). Astragalus polysaccharide reduces inflammatory response by decreasing permeability of LPS-infected Caco2 cells. International journal of biological macromolecules, 61, 347-352.

7. Xue, H., Gan, F., Zhang, Z., Hu, J., Chen, X., \& Huang, K. (2015). Astragalus polysaccharides inhibits PCV2 replication by inhibiting oxidative stress and blocking $N F-\kappa B$ pathway. International journal of biological macromolecules, 81, 22-30.

8. Li, J., Zhong, Y., Li, H., Zhang, N., Ma, W., Cheng, G., ... \& Xu, J. (2011).

Enhancement of Astragalus polysaccharide on the immune responses in pigs inoculated with foot-and-mouth disease virus vaccine. International Journal of Biological Macromolecules, 49(3), 362-368.

9. Kishimoto, T., Akira, S., Narazaki, M., \& Taga, T. (1995). Interleukin-6 family of cytokines and gp130. Blood, 86(4), 1243-1254.

10. Hirano, T., Akira, S., Taga, T., \& Kishimoto, T. (1990). Biological and clinical aspects of interleukin 6. Immunology today, 11, 443-449.

11. Gauldie, J., Richards, C., Harnish, D., Lansdorp, P., \& Baumann, H. (1987). Interferon beta 2/B-cell stimulatory factor type 2 shares identity with monocyte-derived hepatocyte-stimulating factor and regulates the major acute phase protein response in liver cells. Proceedings of the National Academy of Sciences, 84(20), 7251-7255. 
12. Huang, X., Hu, Y., Zhao, X., Lu, Y., Wang, J., Zhang, F., \& Sun, J. (2008). Sulfated modification can enhance the adjuvant activity of astragalus polysaccharide for ND vaccine. Carbohydrate Polymers, 73(2), 303-308.

13. Wright, P. F. (2011). Inductiveleffector mechanisms for humoral immunity at mucosal sites. American Journal of Reproductive Immunology, 65(3), 248-252.

14.Chen H, Shang Y, Yao H, Cui B, Zhang H, Wang Z, Jin H, Li C, Jin N: Immune responses of chickens inoculated with a recombinant fowl pox vaccine co-expressing $H A$ of H9N2 avian influenza virus and chicken IL18. Antiviral Res 2011, 63:50-56

15. Zhang N, Li J, Cheng G, Zhu X, Liu F, Zhang Y, Liu Z, Xu J: Effects of astragalus polysaccharide on the immune response to foot-and-mouth disease vaccine in mice. Carbohyd Polym 2010, 82:680-686.

16.Thekisoe, M. O., Mbati, P. A., \& Bisschop, S. P. R. (2004). Different approaches to the vaccination of free ranging village chickens against Newcastle disease in QwaQwa, South Africa. Veterinary Microbiology, 101, 23-30.

17. Shan, C., Sun, B., Dalloul, R. A., Zhai, Z., Sun, P., Li, M., ... \& Luan, W. (2019). Effect of the oral administration of astragalus polysaccharides on jejunum mucosal immunity in chickens vaccinated against Newcastle disease. Microbial pathogenesis, $135,103621$.

18. Fan, Y., Hu, Y., Wang, D., Guo, Z., Zhao, X., Guo, L., ... \& Nguyen, T. L. (2010). Epimedium polysaccharide and propolis flavone can synergistically stimulate lymphocyte proliferation in vitro and enhance the immune responses to ND vaccine in chickens. International journal of biological macromolecules, 47(2), 87-92.

19. Kong, X. F., Hu, Y. L., Yin, Y. L., Wu, G. Y., Rui, R., Wang, D. Y., \& Yang, C. B. (2006). Chinese herbal ingredients are effective immune stimulators for chickens infected with the Newcastle disease virus. Poultry Science, 85(12), 2169-2175.

20. Hamal, K. R., Burgess, S. C., Pevzner, I. Y., \& Erf, G. F. (2006). Maternal antibody transfer from dams to their egg yolks, egg whites, and chicks in meat lines of chickens. Poultry science, 85(8), 1364-1372.

21. Chen, Y., Wang, D., Hu, Y., Guo, Z., Wang, J., Zhao, X., ... \& Xing, Y. (2010). Astragalus polysaccharide and oxymatrine can synergistically improve the immune efficacy of Newcastle disease vaccine in chicken. International Journal of Biological Macromolecules, 46(4), 425-428.

22. Rothaug, M., Becker-Pauly, C., \& Rose-John, S. (2016). The role of interleukin-6 signaling in nervous tissue. Biochimica et Biophysica Acta (BBA)-Molecular Cell Research, 1863(6), 1218-1227.

23. Scheller, J., Chalaris, A., Schmidt-Arras, D., \& Rose-John, S. (2011). The proand anti-inflammatory properties of the cytokine interleukin-6. Biochimica et Biophysica Acta (BBA)-Molecular Cell Research, 1813(5), 878-888. 
24. Rue, C. A., Susta, L., Cornax, I., Brown, C. C., Kapczynski, D. R., Suarez, D. L., ... \& Afonso, C. L. (2011). Virulent Newcastle disease virus elicits a strong innate immune response in chickens. Journal of general virology, 92(4), 931-939.

25. Sun, Y., Xie, X., He, J., Jiang, J., Niu, R., Bai, Y., \& Li, H. (2013). Enhancement of immune response for Newcastle disease vaccine using a combined adjuvant solution of Astragalus polysaccharides, levamisole, and selenoprotein. Turkish Journal of Veterinary and Animal Sciences, 37(5), 516-522.

26. Rauwa F., Gardin Y., Palya V., Borm S., Gonze M. \& Lemaire S. 2009. Humoral, cell-mediated and mucosal immunity induced by oculo-nasal vaccination of one-day-old SPF and conventional layer chicks with two different live Newcastle disease vaccines. Vaccine. 27(27): 3631-3642.

27. Shan, C., Sun, B., Dalloul, R. A., Zhai, Z., Sun, P., Li, M., ... \& Luan, W. (2019). Effect of the oral administration of astragalus polysaccharides on jejunum mucosal immunity in chickens vaccinated against Newcastle disease. Microbial pathogenesis, $135,103621$. 